\title{
REC-PATH (Recovery Pathways): Overview of a Four- Country Study of Pathways to Recovery from Problematic Drug Use
}

Citation for published version (APA):

Best, D., Vanderplasschen, W., Van de Mheen, D., De Maeyer, J., Colman, C., Vander Laenen, F., Irving, J., Andersson, C., Edwards, M., Bellaert, L., Martinelli, T., Graham, S., Hamer, R., \& Nagelhout, G. E. (2018). REC-PATH (Recovery Pathways): Overview of a Four-Country Study of Pathways to Recovery from Problematic Drug Use. Alcoholism Treatment Quarterly, 36(4), 517-529.

https://doi.org/10.1080/07347324.2018.1488550

Document status and date:

Published: 01/01/2018

DOI:

10.1080/07347324.2018.1488550

Document Version:

Publisher's PDF, also known as Version of record

Document license:

Taverne

Please check the document version of this publication:

- A submitted manuscript is the version of the article upon submission and before peer-review. There can be important differences between the submitted version and the official published version of record.

People interested in the research are advised to contact the author for the final version of the publication, or visit the DOI to the publisher's website.

- The final author version and the galley proof are versions of the publication after peer review.

- The final published version features the final layout of the paper including the volume, issue and page numbers.

Link to publication

\footnotetext{
General rights rights.

- You may freely distribute the URL identifying the publication in the public portal. please follow below link for the End User Agreement:

www.umlib.nl/taverne-license

Take down policy

If you believe that this document breaches copyright please contact us at:

repository@maastrichtuniversity.nl

providing details and we will investigate your claim.
}

Copyright and moral rights for the publications made accessible in the public portal are retained by the authors and/or other copyright owners and it is a condition of accessing publications that users recognise and abide by the legal requirements associated with these

- Users may download and print one copy of any publication from the public portal for the purpose of private study or research.

- You may not further distribute the material or use it for any profit-making activity or commercial gain

If the publication is distributed under the terms of Article $25 \mathrm{fa}$ of the Dutch Copyright Act, indicated by the "Taverne" license above, 


\section{Alcoholism Treatment Quarterly}

\section{REC-PATH (Recovery Pathways): Overview of a Four-Country Study of Pathways to Recovery from Problematic Drug Use}

David Best, Wouter Vanderplasschen, Dike Van de Mheen, Jessica De Maeyer, Charlotte Colman, Freya Vander Laenen, Jamie Irving, Catrin Andersson, Michael Edwards, Lore Bellaert, Thomas Martinelli, Simon Graham, Rebecca Hamer \& Gera E. Nagelhout

To cite this article: David Best, Wouter Vanderplasschen, Dike Van de Mheen, Jessica De Maeyer, Charlotte Colman, Freya Vander Laenen, Jamie Irving, Catrin Andersson, Michael Edwards, Lore Bellaert, Thomas Martinelli, Simon Graham, Rebecca Hamer \& Gera E. Nagelhout (2018) REC-PATH (Recovery Pathways): Overview of a Four-Country Study of Pathways to Recovery from Problematic Drug Use, Alcoholism Treatment Quarterly, 36:4, 517-529, DOI: 10.1080/07347324.2018.1488550

To link to this article: https://doi.org/10.1080/07347324.2018.1488550

Published online: 06 Jul 2018.

Џll Article views: 308

View Crossmark data ¿
Submit your article to this journal $\sqsubset$
Q View related articles $\longleftarrow$

Citing articles: 3 View citing articles $\llbracket$ 


\title{
REC-PATH (Recovery Pathways): Overview of a Four-Country Study of Pathways to Recovery from Problematic Drug Use
}

\author{
David Best (10), Wouter Vanderplasschen ${ }^{\mathrm{b}}$, Dike Van de Mheen ${ }^{\mathrm{c}}$, \\ Jessica De Maeyerd, Charlotte Colman ${ }^{\mathrm{e}}$, Freya Vander Laenene, Jamie Irving a \\ Catrin Andersson ${ }^{\mathrm{a}}$, Michael Edwards (iD) ${ }^{\mathrm{a}}$, Lore Bellaert ${ }^{\mathrm{b}}$, Thomas Martinelli ${ }^{\mathrm{c}, \mathrm{f}}$, \\ Simon Graham ${ }^{a}$, Rebecca Hamer ${ }^{\mathrm{a}}$, and Gera E. Nagelhout ${ }^{\mathrm{f}, \mathrm{g}}$
}

\begin{abstract}
aDepartment of Law and Criminology, Sheffield Hallam University, Sheffield, England; 'bepartment of Special Needs Education, Ghent University, Ghent, Belgium; 'Tranzo Scientific Center for Care and Welfare, Social and Behavioural Sciences, Tilburg University, Tilburg, the Netherlands; ${ }^{\mathrm{d} C e n t r e}$ of Expertise on Quality of Life, Faculty of Health, Education and Social Work, University College Ghent, Belgium; 'Department of Criminology, Criminal Law and Social Law, Ghent University, Ghent, Belgium; fIVO Addiction Research Institute, The Hague, the Netherlands; ' Department of Family Medicine, Maastricht University (CAPHRI), Maastricht, the Netherlands
\end{abstract}

\begin{abstract}
Although there has been a growth in recent years in recovery research, much of this has been from the United States, and there is very little comparative research in this area. This article describes the rationale, conceptual foundations and methods for a prospective, multicountry, cohort study aimed to map pathways to recovery from problematic illicit drug use, with a specific focus on gender differences in recovery pathways. This study combines qualitative and quantitative components and examines the impact of recovery policy on the accessibility and viability of recovery pathways in England, Scotland, Belgium, and The Netherlands. Additionally, the article describes five processes through which mechanisms for behavior change for recovery may be triggered. This study will provide opportunities for linking recovery outcome research with analyses of national recovery policies, while also addressing the gap in literature around female pathways to recovery.
\end{abstract}

\section{KEYWORDS}

Recovery pathways; gender; policy; mechanisms of change; life in recovery

\section{Introduction}

In a review of evidence for the Substance Abuse and Mental Health Services Administration (SAMHSA), Sheedy and Whitter (2009) estimate that of all those who have a lifetime alcohol or drug dependence $58 \%$ will achieve stable recovery. White (2012) also estimates a recovery rate of approximately 50\% based on an extensive review of literature. This represents a rather optimistic prognosis for what is often categorized as a chronic relapsing condition

CONTACT David Best d.best@shu.ac.uk Department of Law and Criminology, Sheffield Hallam University, Room 213, Heart of the Campus, 41 Collegiate Crescent, Sheffield, S10 2BQ, England 
(O’Brien \& McLellan, 1996; White, Boyle, \& Loveland, 2003) and is consistent with a model of recovery based on hope and belief that change is possible.

Research assessments of who achieves this stable recovery status has generated a body of research into "recovery capital," defined as the internal and external resources available to an individual to support their recovery endeavours (Granfield \& Cloud, 2001). Subsequently, Cloud and Granfield (2008) extended this concept to "negative recovery capital" to suggest that for certain populations the likelihood of recovery is diminished, suggesting that this applies to older drug users, to female drug users, to users with a significant forensic history, and to individuals with comorbid mental health problems. However, models of recovery capital have had to be developed to incorporate community-related factors (Cano, Best, Edwards, \& Lehman, 2017), and concerns remain that recovery capital may overstate the importance of personal factors at the expense of structural and community determinants of change.

This has also prompted research into the potential mechanisms that may support and sustain recovery endeavors. Moos (2008) cites four such mechanisms, two social and two personal mechanisms. He argues that recovery was more likely where there were opportunities for social learning and where networks provided social control in the form of norms and values that are supportive of recovery. Similarly, individuals were more likely to recover if their values changed so that the attractiveness of recovery exceeded the appeal of return to use, which he refers to as "behavioural economics." Finally, Moos suggests that the development of a range of coping skills including resilience and self-esteem can help individuals manage high-risk situations. The social model is supported by a secondary analysis of Project MATCH data by Longabaugh, Wirtz, Zywiak, and O’Malley (2010) who found that transitioning from social groups supportive of drinking to social groups supportive of recovery was a major predictor of sustained recovery endeavors in problem drinkers.

This theme was further developed in a recent document by John Kelly (2017) on mechanisms for behavior change for recovery in Alcoholics Anonymous (AA). Kelly argues that social network change (along with cognitive transformations) was critical in male recovery, but that increases in abstinence self-efficacy was the primary mechanism of behavior change brought about by attendance at 12-Step mutual aid groups. In challenging the importance of a "spiritual awakening," Kelly also argued that the evidence would suggest a gender difference-the effective elements of 12-Step related more strongly to social factors in men and to cognitive factors in women (particularly the growth of abstinence self-efficacy).

There is a gap in knowledge about how different approaches to supporting recovery from problematic drug use generate mechanisms of change toward stable recovery. Additionally, most recovery research has been performed in the 
United States and Australia, but research in Europe, especially multicountry studies, are missing. Therefore, the current Recovery Pathways (REC-PATH) study examines with a prospective design how different approaches to supporting recovery, including 12-Step mutual aid groups, generate such mechanisms for change in four European countries. Prior to outlining this model, the programs of research that the REC-PATH study builds on will be described, namely, the Life in Recovery (LiR) series of surveys and the Social Networks and Recovery study.

\section{Life in recovery}

In 2012, the U.S. recovery advocacy organization Faces and Voices of Recovery, 2013 published the first national survey in the United States on recovery journeys: the LiR survey. The results of the online survey showed consistent improvements of people in recovery across domains as diverse as social relationships, health, community involvement, employment, and involvement with the criminal justice system. Furthermore, greater improvements were typically associated with longer duration of recovery. Across a diverse range of recovery types (e.g." "in recovery," medication-assisted recovery), participants reported consistent improvements across diverse areas of wellbeing. Using adaptations of the same approach, the survey has since been repeated in Australia (Best et al., 2014), the United Kingdom (Best et al., 2015), and Canada (McQuaid et al., 2017). The results have been remarkably consistent with strong gains in each of the domains assessed and have been used to inform policy and practice debates in each of these countries about the benefits associated with sustained and stable recovery.

\section{Social Networks and Recovery (SONAR)}

Monash University, Deakin University, and the University of Queensland in Australia carried out a longitudinal study, funded by the Australian Research Council (ARC) that assessed the impact of changes in social networks and social identity on a cohort of more than 300 drug and alcohol users recruited as they entered treatment at one of five Therapeutic Communities on the east coast of Australia (Best, Haslam et al., 2016). The project involved interviewer-administered research assessments conducted around the time of treatment admission, and two follow-ups, the first follow-up around 6 months after baseline, approximately the time those who had completed the program would be due to leave, and the second follow-up 12 months after baseline when they would all have returned to the community. The project was essentially an attempt to test the social identity model of recovery (SIMOR; Best, Beckwith et al., 2016), a conceptual approach to recovery that emphasizes the importance of social network change in initiating and sustaining recovery. However, the model asserts that 
simply moving between social groups is not sufficient, as it is the identity that is linked to old and new groups that is crucial in transitioning values and beliefs to ones that could support and sustain recovery.

The project was also used to further enhance a research and therapeutic visualisation technique called social identity mapping (SIM; Best et al., 2015). This technique was developed to allow rapid assessment of the size and composition of the social network and the extent to which it was protective against substance use, using a method that actively involved and engaged the research participant. Recovery is sustained by moving away from groups whose norms are centered around substance use; moving away from such groups to those whose norms do not support heavy substance use requires a change in social network composition. The SIM method is highly engaging for clients, allowing a hitherto hidden visualization and understanding of the negative impact that engagement with groups supporting substance use norms are having on recovery efforts. It is a strong therapeutic tool that also yields quantitative and qualitative research data.

The project allowed the development of a set of measures that assess pathways to recovery primarily from a social perspective, and the extension of the design of SONAR for the REC-PATH study allowed application beyond the Therapeutic Community setting to a more diverse range of recovery models and pathways.

\section{Aim of the REC-PATH study}

The aim of our current project, called Recovery Pathways (REC-PATH), is to map pathways to recovery from problematic illicit drug use in populations engaging with five different mechanisms of behavior change for recovery:

1, 12-Step mutual aid support

2, peer-based recovery support

3 , residential and community treatment

4 , specialist outpatient treatment (maintenance and abstinence oriented)

5 , through their own "natural recovery" endeavors.

With the exception of natural recovery that assumed no sustained engagement with either peer support or professional treatment, the assumption was that many of the participants may have attempted multiple methods, and our aim was to assess sequencing, impact, and effectiveness of each pathway and combination.

Following the categorization specified by the Betty Ford Institute Consensus Panel (2007), we will recruit populations in early $(<1$ year), sustained ( $1-5$ years), and stable recovery ( $>5$ years) in four countries (England, Scotland, Belgium, and The Netherlands) using LiR as the screening tool, and then track these individuals over the course of one year, with baseline and one-year follow-up in-depth interviews. The objective is to examine how the mechanisms for behavior change that are identified in 
the previous work of Moos (2008) and Kelly (2017) apply at different stages of recovery journeys. Eventually, this can provide indications for how treatment, interventions, and quality of life of people in recovery can be enhanced, and recovery can be sustained. These support-delivering mechanisms are explained in more detail in Table 1 and in the text below:

1. 12-Step mutual aid: This is globally the most widespread form of selfhelp (Humphreys et al., 2004; Kelly, 2017) and is based on the 12 Steps of Alcoholics Anonymous that have been adapted for a number of other 12-Step fellowships including Narcotics Anonymous, Cocaine Anonymous, and Gamblers Anonymous. The assumption underpinning this recovery model is that addiction is a lifelong, chronic affliction that can be effectively managed by working the 12-Step program.

2. Other peer-based support groups: There are an eclectic range of other peer-based organizations from the highly structured and programmatic such as self-managed addiction recovery training (SMART) (Horvath, 2000; Horvath \& Yeterian, 2012) to small groups of like-minded people who come together to support each other's recovery. These are collectively referred to as peer-based recovery support services (PBRSS) by White (2009).

3. Professional community treatment: This is a diverse group of professional treatments that will include counselling and other outpatient therapeutic interventions as well as pharmacotherapies such as opioid substitution (maintenance) therapies that have been the subject of considerable interest regarding the idea of "medication-assisted recovery" (e.g., White \& Torres, 2010).

4. Residential treatment: this will include Therapeutic Communities (TC), that is of particular interest to the study, because of its unique philosophy and approach based on the idea of the community, and the process of living in a TC, as the method of achieving recovery (De Leon, 2000; Vanderplasschen et al., 2013). However, this category will also include a more varied array of residential rehabilitative facilities, including those that are staffed exclusively by paid professionals.

5. To supplement these four forms of active intervention that we examine, we will also consider a fifth pathway to recovery change, which has been termed "natural recovery." Natural recovery (e.g., Klingemann \& Sobell, 2001; Sobell, Ellingstad, \& Sobell, 2000) refers to those individuals who achieve and sustain recovery with no significant input from formal assistance or treatment for substance use problems, nor from support offered by mutual aid groups.

The aim of the study is to assess the utilization and uptake of each of these support-delivering mechanisms and their perceived effectiveness and impact among people in recovery at different stages of their recovery journey: early 


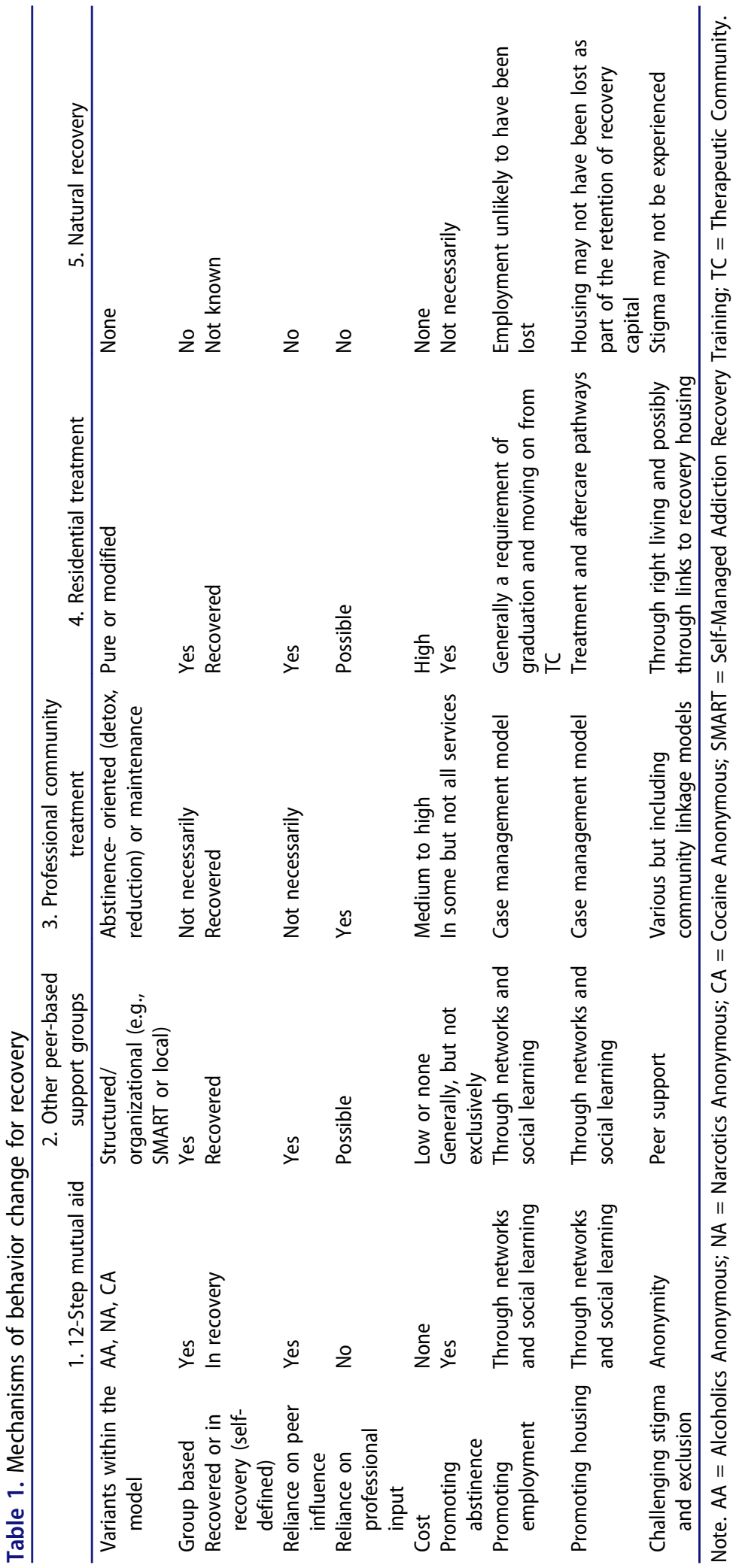


recovery (within the first year), sustained recovery (between one and 5 years into the recovery journey), and stable recovery (more than 5 years into the recovery journey). Also, encouraged by the gender breakdown of the previous LiR surveys, we are aiming to recruit equal numbers of male and female participants from each of the stages of recovery to examine gender differences in uptake, utilization, and satisfaction with each of these projects.

The following research questions are answered in the REC-PATH study:

1. What are the characteristics of those in early, sustained and stable recovery in England, Scotland, Belgium, and The Netherlands and how do they vary by gender and by experiences of the five mechanisms of behavior change for recovery (MOBCR) at baseline? How have characteristics of those in different recovery stages changed by one-year follow-up?

2. How often have participants experienced each of the MOBCR and at what stage of their addiction/recovery trajectory at baseline survey assessment? How has this changed by one-year follow-up, and what impact have those changes had on their well-being?

3. What are the typical combinations of MOBCR and to what extent do these vary by gender, country, and recovery stage at baseline? How has this changed by one-year follow-up?

4. Are there significant baseline differences in the levels of housing stability, employment, family engagement and QoL as a function of (a) recovery stage, (b) MOBCR and combination of these mechanisms, (c) country, (d) gender, and (e) baseline social identity and recovery capital? How has this changed by one-year follow-up?

5. For each staged group (early, sustained, and stable recovery), what is the evidence of positive recovery growth in the key outcome domains of recovery capital, social identity, QoL, employment, housing, and family engagement from baseline to one-year follow-up? Do these vary by country, gender, or MOBCR, and what appear to be the structural barriers and enablers for continuing recovery growth?

6. How do drug users in various stages of recovery experience recovery and access various sources of (social) recovery capital? In particular, what differential barriers/resources do men and women experience in their recovery process and how do women portray their recovery process?

7. What are the predictors of relapse (reinstatement of any form of problematic drug use) and loss of community reintegration, by gender, country, and recovery stage? If there is relapse, what are the mechanisms used to reinstate recovery and how effective are they?

8. What are the indicators of impact of national policies on recovery journeys and utilization of different MOBCR? Are there particular policy applications that target women and is this manifest in either the qualitative or quantitative data? What are the differences between countries? 
9. What recommendations for adequate recovery policies can be formulated based on service users' and user organisations' experiences?

\section{Methods}

\section{Quantitative surveys}

The quantitative part of the REC-PATH study starts with a structured and standardized survey about lifetime recovery experiences, called Life in Recovery (LiR; updated from the UK Life in Recovery survey), that will be used as a screening mechanism to recruit a drug recovery sample in four countries: Scotland, England, Belgium, and The Netherlands. There have only been minor amendments from the surveys reported in Australia (Best, 2015) and England (Best et al, 2015).

Inclusion criteria are being a minimum age 18 years and being in recovery from problematic illicit drug use for at least 3 months. The concept of "recovery" is self-defined by respondents and could mean complete abstinence from illicit drugs but could also mean that respondents are still using illicit drugs but no longer in a problematic way. Recovery from alcohol use is not examined in this study, though people may have comorbid problematic alcohol use, which is assessed in the survey. We will attempt to recruit equal populations of people in early recovery ( $<1$ year), sustained recovery ( $1-5$ years), and stable recovery ( $>5$ years), stratified so that there are equal numbers of men and women, as gendered pathways are a key focus of the study. We will recruit through the key recovery agencies and treatment services, through social media, and through word-of-mouth snowballing in each participating country.

We are aiming for a total of 250 respondents to the LiR survey that is our inclusion screen, per country, providing us with an initial sweep of around 1,000 LiR surveys. No incentives are given for participation in the LiR survey. Respondents can fill in the survey online or on paper. The survey asks about the five mechanisms of behavior change for recovery, ever and past 30-day drug use, barriers and facilitators to recovery, experiences during periods of problematic drug use, and experiences during recovery.

For those who complete the LiR survey meeting the inclusion survey and expressing willingness to participate, there is a more extensive survey that will be carried out among 150 respondents per country,providing baseline quantitative data on 600 participants in total. This Outcome Study at Baseline (OSB) survey comprises standardized measures that will adequately address the research questions. Measures in the OSB include COMMITMENT TO SOBRIETY (Kelly \& Greene, 2014), Recovery Group Participation Scale (Groshkova, Best, \& White, 2011), Maudsley Addiction Profile (Marsden et al., 1998), manchester short assessment of quality of life (MANSA) (Björkman \& Svensson, 2005), and 
Perceived Stigma (Link, Struening, Phelan, \& Nuttbrock, 1997). The OSB survey will be carried out within 1 to 3 months after participation in the LiR survey. An incentive of $€ 10 / £ 10$ is given for participation in this survey. Respondents can fill in the survey online, on paper, by telephone, or face-to-face, whichever they prefer. The questionnaire contains questions about, for example, quality of life, key life events, physical and psychological health, barriers and facilitators to recovery, past 30-day drug use, perceived stigmatization, social networks, and social identity.

Finally, we aim to reassess the cohort one year after the baseline survey, using a repeated-measures approach; a direct replication of the OSB items. The follow-up survey, Outcome Study Follow-up (OSF), will be conducted among the respondents who participated in the OSB. Attrition will be mitigated by continual engagement with this cohort via social media, a dedicated closed group on Facebook, and email. OSF participants are incentivised further by the offer of $€ 15 / £ 15$ given for completing the OSF part of the study. In addition to repeating the measures from OSB, OSF will include questions exploring a range of behaviors and changes during the past 12 months.

\section{Qualitative studies}

Subsamples of 30 respondents per country will be interviewed between the first (OSB) and second follow-up survey (OSF), using in-depth qualitative interviewing techniques. The aim of these interviews is to understand the subjective experience of attempting to access various sources of recovery capital and change mechanisms, including experiences with specialist treatment services (Kelly, 2017), and the nature and success of self-change attempts (natural recovery). Additionally, the in-depth qualitative interview will consist of individual, retrospective narratives to reflect the complexity of the recovery concept and the recovery journey. To facilitate this, the interview will be based on the lifeline interview method (LIM; Berends, 2011). LIM is a cross-sectional method, allowing a retrospective lens to elicit autobiographical, longitudinal data covering personal recovery trajectories. The results from the quantitative cohort study will inform the qualitative interview schedule.

The innovative Photovoice methodology (Vervliet, Reynaert, Verelst, Vindevogel, \& De Maeyer, 2017) will be used among 15 women in recovery in Belgium to further explore and document their recovery pathways. These women are provided with cameras and are asked to photograph key recovery moments and experiences, thus gaining insight in structural barriers and facilitators of recovery. Photographs are discussed and analyzed during group meetings and potential additional individual interviews. This study will address the gap in literature around female pathways to recovery in one of our participating sites. 


\section{Policy analysis}

A policy analysis is being conducted across the four participating countries. As the four countries differ in the way and extent to which recovery is translated into the national addiction policy, comparisons between these countries can be particularly informative. The aim of this analysis is to explore how policy makers understand the process of addiction recovery and how that can be realized through various policy and practice activities. In each country, a focus group with key policy stakeholders in the addiction field, such as (top level) civil servants, is performed to start off the policy analyses. This is followed by documentary analyses of policy and related documents (e.g., official statistics) and face-to-face interviews with civil servants as well as politicians, experts by experience, academics, and practitioners. The aim of this policy analysis is to identify how policy makers define recovery, what strategies and structures are implemented to achieve the identified recovery models and objectives, and whether the objectives are implemented as intended as well as achieved as intended. The results from the quantitative and qualitative components of this study will be interpreted in light of the results from the policy analyses. We will look to undertake structured analysis of the documents and the interview transcripts.

\section{Discussion}

The aim of the REC-PATH study is to map pathways to recovery in populations engaging with different mechanisms of behavior change for recovery-mutual aid, peer-based support, residential and community treatment, specialist treatment: (maintenance and abstinence oriented) or through their own "natural recovery" endeavors, at different stages of their addiction careers. The study is the first major comparative study of addiction recovery undertaken in Europe and will allow us to look at what mechanisms help to initiate and support recovery and how this differs by gender.

Examining how different forms of support and intervention generate mechanisms for sustainable behavior change in recovery will shed further light on how treatment pathways and policy preferences influence the accessibility and viability of these pathways. Although the study builds on previous work on LiR and the SONAR study conducted in Australia, REC-PATH will use a number of the same instruments to test the same underlying SIM of recovery, extending the design to move from one particular intervention modality (TCs) to five (four types of intervention and natural recovery). As the study also uses a prospective cohort design, we will be able to examine active engagement with any of these change triggers as predictors of growth of recovery resources and recovery capital. 
Furthermore, we will have two further components to the study to supplement the predominantly quantitative and structured approach of the outcome component of the study. The first is the use of qualitative techniquesincluding innovative methods such as Photovoice-to supplement the quantitative measures, and this will include timeline follow-back methods to examine changes and pathways of recovery across the life course. The second critical additional component of the research program is the opportunity to conduct a policy analysis across the four participating countries. Broadly speaking these can be characterized as having established recovery policies in Scotland (Scottish Government, 2008) and England (HM Government, 2010) and relatively new recovery policies in The Netherlands (GGZ Nederland, 2013) and Belgium (Ministerie van Welzijn, Volksgezondheid en Gezin, 2015). We will review the policy frameworks for recovery and then examine the impact of the policy and practice frameworks on the recovery pathways reported in the client-driven components of the study.

Finally, the overall program of research will have an approach and a procedure that are consistent with the recovery paradigm of inclusivity and transparency. To this end, we will have a website and social media accounts and will recruit through the key recovery agencies and services and directly in each participating country. Our aim is to ensure that the voices of those in recovery are heard and that their stories are given the opportunity to be aired.

\section{Funding}

This work is supported in the UK by Department of Health/National Institute for Health Research (NIHR) and Scottish Government, in Belgium by Belgian Science Policy (BELSPO) \& Research Foundation - Flanders (FWO), and in Netherlands by ZonMw, The Netherlands Organisation for Health Research \& Development.

\section{ORCID}

David Best (1) http://orcid.org/0000-0002-6792-916X

Michael Edwards (1) http://orcid.org/0000-0003-2866-9200

\section{References}

Berends, L. (2011). Embracing the visual: Using timelines with in-depth interviews on substance use and treatment. The Qualitative Report, 16(1), 1-9.

Best, D. (2015). Life in Recovery in Australia. Melbourne, Australia: Turning Point.

Best, D., Albertson, K., Irving, J., Lightowlers, C., Mama-Rudd, A., \& Chaggar, A. (2015). The UK life in recovery survey 2015: The first national UK survey of addiction recovery experiences. Sheffield, UK: Helena Kennedy Centre for International Justice, Sheffield Hallam University. Best, D., Beckwith, M., Haslam, C., Alexander Haslam, S., Jetten, J., Mawson, E., \& Lubman, D. I. (2016). Overcoming alcohol and other drug addiction as a process of social identity 
transition: The social identity model of recovery (SIMOR). Addiction Research \& Theory, 24, 111-123. doi:10.3109/16066359.2015.1075980

Best, D., Haslam, C., Staiger, P., Dingle, G., Savic, M., Bathish, R., ... Lubman, D. I. (2016). Social networks and recovery (SONAR): Characteristics of a longitudinal outcome study in five therapeutic communities in Australia. Therapeutic Communities: the International Journal of Therapeutic Communities, 37, 131-139. doi:10.1108/TC-04-2016-0012

Best, D. I., Lubman, D., Savic, M., Wilson, A., Dingle, G., Alexander Haslam, S., \& Jetten, J. (2014). Social and transitional identity: Exploring social networks and their significance in a therapeutic community setting. Therapeutic Communities: the International Journal of Therapeutic Communities, 35, 10-20. doi:10.1108/TC-04-2013-0007

Betty Ford Institute Consensus Panel. (2007). What is recovery? A working definition from the betty ford institute. Journal of Substance Abuse Treatment, 33, 221-228. doi:10.1016/j.jsat.2007.06.001

Björkman, T., \& Svensson, B. (2005). Quality of life in people with severe mental illness. Reliability and validity of the Manchester short assessment of quality of life (MANSA). Nordic Journal of Psychiatry, 59(4), 302-306. doi:10.1080/08039480500213733

Cano, I., Best, D., Edwards, M., \& Lehman, J. (2017). Recovery capital pathways: Mapping the components of recovery wellbeing. Drug and Alcohol Dependence, 181, 11-19. doi:10.1016/ j.drugalcdep.2017.09.002

Cloud, W., \& Granfield, R. (2008). Conceptualizing recovery capital: Expansion of a theoretical construct. Substance Use \& Misuse, 43, 1971-1986. doi:10.1080/10826080802289762

De Leon, G. (2000). The therapeutic community: Theory, model, and method. New York, NY: Springer Publishing Co.

Faces and Voices of Recovery. (2013). Life in recovery: Report on the survey findings. Washington, DC.

GGZ Nederland. (2013). Een visie op verslaving en verslavingszorg: Focus op preventie en herstel [A vision on addiction and addiction care: Focus on prevention and recovery]. Ede, NL: Author.

Granfield, R., \& Cloud, W. (2001). Social context and "natural recovery": The role of social capital in the resolution of drug-associated problems. Substance Use \& Misuse, 36, 1543-1570. doi:10.1081/JA-100106963

Groshkova, T., Best, D., \& White, W. (2011). Recovery group participation scale (RGPS): Factor structure in alcohol and heroin recovery populations. Journal of Groups in Addiction \& Recovery, 6, 76-92. doi:10.1080/1556035X.2011.571132

HM Government. (2010). Drug strategy 2010. Reducing demand, restricting supply, building recovery: Supporting people to live a drug free live. London: Home Office.

Horvath, A. T. (2000). Smart recovery ${ }^{\circledR}$ Addiction recovery support from a cognitive-behavioral perspective. Journal of Rational-Emotive and Cognitive-Behavior Therapy, 18, 181-191.

Horvath, A. T., \& Yeterian, J. (2012). SMART recovery: Self-empowering, science-based addiction recovery support. Journal of Groups in Addiction \& Recovery, 7, 102-117. doi:10.1080/1556035X.2012.705651

Humphreys, K., Wing, S., McCarty, D., Chappel, J., Gallant, L., Haberle, B., ... Weiss, R. (2004). Self-help organizations for alcohol and drug problems: Toward evidence-based practice and policy. Journal of Substance Abuse Treatment, 26, 151-158. doi:10.1016/S0740-5472(03)00212-5

Kelly, J. F. (2017). Is alcoholics anonymous religious, spiritual, neither? findings from 25 years of mechanisms of behavior change research. Addiction, 112, 929-936. doi:10.1111/add.13590

Kelly, J. F., \& Greene, C. M. (2014). Beyond motivation: Initial validation of the commitment to sobriety scale. Journal of Substance Abuse Treatment, 46(2), 257-263. doi:10.1016/j.jsat.2013.06.010

Klingemann, H. K. H., \& Sobell, L. C. (2001). Introduction: Natural recovery research across substance use. Substance Use \& Misuse, 36, 1409-1416. doi:10.1081/JA-100106957 
Link, B. G., Struening, E. L., Phelan, J. C., \& Nuttbrock, L. (1997). On stigma and its consequences: Evidence from a longitudinal study of men with dual diagnoses of mental illness and substance abuse. Journal of Health and Social Behaviour, 38(2), 177-190. doi: $10.2307 / 2955424$

Longabaugh, R., Wirtz, P. W., Zywiak, W. H., \& O’malley, S. S. (2010). Network support as a prognostic indicator of drinking outcomes: The COMBINE study. Journal of Studies on Alcohol and Drugs, 71, 837-846. doi:10.15288/jsad.2010.71.837

Marsden, J., Gossop, M., Stewart, D., Best, D., Farrell, M., \& Strang, J. (1998). The maudsley addiction profile: A brief instrument for treatment outcome research. Addiction, 93(12), 1857-1867. doi:10.1046/j.1360-0443.1998.9312185711.x

McQuaid, R. J., Malik, A., Moussouni, K., Baydack, N., Stargardter, M., \& Morrisey, M. (2017). Life in recovery from addiction in Canada. Ottawa, Ontario: Canadian Centre on Substance Use and Addiction.

Ministerie van Welzijn, Volksgezondheid en Gezin. (2015). Visienota: Naar een geïntegreerde en herstelgerichte zorg voor mensen met een verslavingsprobleem [Vision statement: To an integrated and recovery focused care for people with an addiction problem]. Brussels, BE: Author.

Moos, R. H. (2008). Active ingredients of substance use-focused self-help groups. Addiction, 103, 387-396. doi:10.1111/add.2008.103.issue-3

O'Brien, C., \& McLellan, A. T. (1996). Myths about the treatment of addiction. The Lancet, 347, 237-240. doi:10.1016/S0140-6736(96)90409-2

Scottish Government. (2008). The road to recovery. A new approach to tackling Scotland's drug problem. Edinburgh, UK: Author.

Sheedy, C. K., \& Whitter, M. (2009). Guiding principles and elements of recovery-oriented systems of care: What do we know from the research? HHS Publication No. (SMA) 09-4439. Rockville, MD: Center for Substance Abuse Treatment, Substance Abuse and Mental Health Services Administration.

Sobell, L. C., Ellingstad, T. P., \& Sobell, M. B. (2000). Natural recovery from alcohol and drug problems: Methodological review of the research with suggestions for future directions. Addiction, 95, 749-764. doi:10.1046/j.1360-0443.2000.95574911.x

Vanderplasschen, W., Colpaert, K., Autrique, M., Rapp, R. C., Pearce, S., Broekaert, E., \& Vandevelde, S. (2013). Therapeutic communities for addictions: A review of their effectiveness from a recovery-oriented perspective. The Scientific World Journal, 2013, 427817. doi:10.1155/2013/427817

Vervliet, M., Reynaert, D., Verelst, A., Vindevogel, S., \& De Maeyer, J. (2017). “If you can't follow, you are out." The perspectives of people with mental health problems on citizenship. Applied Research Quality of Life. doi:10.1007/s11482-017-9537-4

White, W., Boyle, M., \& Loveland, D. (2003). Addiction as chronic disease: From rhetoric to clinical application. Alcoholism Treatment Quarterly, 3/4, 107-130.

White, W. (2009). Peer-based Addiction Recovery Support: History, Theory, Practice, and Scientific Evaluation. Chicago, IL: Great Lakes Addiction Technology Transfer Center and Philadelphia Department of Behavioral Health and Mental Retardation Services.

White, W. L. (2012). Recovery/remission from substance use disorders: An analysis of reported outcomes in 415 scientific reports, 1868-2011. Drug \& alcohol findings review analysis. Pittsburgh, PA: Philadelphia Department of Behavioral Health and Intellectual disAbility Services and the Great Lakes Addiction Technology Transfer Center.

White, W. L., \& Torres, L. (2010). Recovery-oriented methadone maintenance. Chicago, IL: the Great Lakes Addiction Technology Transfer Center, the Philadelphia Department of Behavioral Health and Mental Retardation Services, and the Northeast Addiction Technology Transfer Center. 